\title{
RNA-seq analysis provides insights into cold stress responses of Xanthomonas citri pv. citri
}

\author{
Jin-Xing Liao ${ }^{1,2+}$, Kai-Huai Li ${ }^{1,2+}$, Jin-Pei Wang ${ }^{1,2}$, Jia-Ru Deng ${ }^{1,2}$, Qiong-Guang Liu ${ }^{1,2}$ and Chang-Qing Chang ${ }^{1,2^{*}}$
}

\begin{abstract}
Background: Xanthomonas citri pv. citri (XCC) is a citrus canker causing Gram-negative bacteria. Currently, little is known about the biological and molecular responses of Xcc to low temperatures.

Results: Results depicted that low temperature significantly reduced growth and increased biofilm formation and unsaturated fatty acid (UFA) ratio in Xcc. At low temperature Xcc formed branching structured motility. Global transcriptome analysis revealed that low temperature modulates multiple signaling networks and essential cellular processes such as carbon, nitrogen and fatty acid metabolism in Xcc. Differential expression of genes associated with type IV pilus system and pathogenesis are important cellular adaptive responses of Xcc to cold stress.
\end{abstract}

Conclusions: Study provides clear insights into biological characteristics and genome-wide transcriptional analysis based molecular mechanism of Xcc in response to low temperature.

Keywords: Xanthomonas, Low temperature stress, Motility, Biofilm formation, Fatty acids, Metabolism

\section{Background}

Plant diseases cause significant crop losses worldwide and development of effective disease control requires understanding the mechanisms of plant diseases [1]. Biological and non-biological factors can contribute in the development of plant diseases. Plant-pathogen interaction mediates biological factors of plant diseases. Environmental factors drive pathogens to adjust in the adverse environment to develop plant diseases [2]. Current advancements in phytopathology have provided extensive knowledge about host-pathogen relationship and environment $[3,4]$.

Low temperature is one of the most prevalent abiotic stresses. Different mechanisms among species facilitate to adapt during temperature changes and plant responses to cold stress have been extensively studied [5-8]. Cellular mechanisms such as RNA processing and nucleocytoplasmic transport play crucial roles in plant stress [9]. $\mathrm{Ca}^{2+}$

\footnotetext{
* Correspondence: changca@scau.edu.cn

${ }^{\dagger}$ Jin-Xing Liao and Kai-Huai Li contributed equally to this work.

'Integrative Microbiology Research Centre, South China Agricultural

University, No. 483 Wushan RoadTianhe, Guangzhou 510642, People's

Republic of China

${ }^{2}$ Department of Plant Pathology, Guangdong Province Key Laboratory of Microbial Signals and Disease Control, South China Agricultural University, No. 483 Wushan RoadTianhe, Guangzhou 510642, People's Republic of China
}

signaling pathway and salicylic acid (SA) also participate in responding to low temperature stress [10-12].

Impact of low temperature in the regulation of bacterial physiology has been reported. For example, L. monocytogenes was reported to evolve multiple adaptive response pathways under cold stress including change in the composition of membrane fatty acids to regulate membrane fluidity $[13,14]$. E. coli adapts to low temperature environment by increasing the ratio of straight-chain unsaturated fatty acids (SCUFA) to straight-chain saturated fatty acids (SCFAs) [15]. In Bacillus subtilis, stress response to low temperatures involve proteins of translation machinery and membrane adaptation [16]. In general, bacteria adapt to low temperature environment by regulating several cellular factors such as fatty acid desaturases [17], cold shock proteins (CSPs) [18] and transcriptional regulators [14, 19-21].

Gram-negative bacteria, Xanthomonas is a pathogen of about 400 plant hosts including rice, citrus, banana, cabbage, tomatoes, pepper and beans [22]. Xanthomonas citri pv. citri is an important pathogen that causes citrus canker and has an optimum growth temperature of 20 $30{ }^{\circ} \mathrm{C}$ with minimum range of $5-10^{\circ} \mathrm{C}$ and the highest of $35^{\circ} \mathrm{C}$. At high temperature, $\mathrm{Xcc}$ rapidly reproduces in host tissues to cause immense proliferation of host cells 
resulting in the expansion and rupture of epidermal tissue, suberification and mass death of plant tissues [23]. China, Brazil, U.S.A., India, Mexico, and Spain are world's leading citrus growing countries. In China, citrus plants are mainly grown in southern China [24] and autumn temperature decreases up to $15^{\circ} \mathrm{C}$ [25]. Although, plant response to cold stress has been extensively studied [5-8], but limited information is available about the impact of low temperature on plant pathogen, Xanthomonas. To gain insight into the molecular mechanisms of $X c c$ in response to low temperature, RNA-seq technology was employed along with physiological experiments to examine the spectrum and impact of low temperature on gene expression profiles and physiological changes in Xcc.

\section{Results}

\section{Negative effects of low temperature on Xcc growth}

Temperature is a crucial environmental factor that determines the growth of pathogens [26]. To investigate the effect of temperature change on $X c c$, the growth of wild-type strain was anlyzed (OD $600 \mathrm{~nm}$ ) at $28^{\circ} \mathrm{C}$ and $15^{\circ} \mathrm{C}$ in YEB medium. Xcc exhibited slower growth at low temperature and different lag phases at different temperatures (Fig. 1a). Colony forming units (CFU) of $X c c$ strain in different growth phases at $15^{\circ} \mathrm{C}$ and $28^{\circ} \mathrm{C}$ were measured by dilution plate count method, which revealed significant effect of low temperature on Xcc growth (Fig. 1b).

\section{Effects of low temperature on swarming motility and biofilm formation of Xcc}

Motility is an important virulence trait of bacterial pathogens as it facilitates attachment to host surfaces and colonization of different environments [27, 28]. Biofilms are essential for environmental persistence especially when organisms are undergoing temperature changes. Comparative analysis of Xcc motility and biofilm formation at $28^{\circ} \mathrm{C}$ and $15^{\circ} \mathrm{C}$ revealed that biofilm formation was increased at low temperature (Fig. 2a). At different temperatures, $X c c$ biofilm formation was also observed on interstitial surfaces between glass slides and nutrient-agar medium. At low temperature bacteria densely gathered to form closely packed biofilm layer (Fig. 2b). These biofilms were observed as dynamic communities that split into small groups of "pioneer" cells to colonize a new environment [29] (Fig. 2c). Colonization phase occurred at the temperatures higher than $28^{\circ} \mathrm{C}$ whereas significantly reduced swarming mobility of $\mathrm{Xcc}$ was noted at low temperature (Fig. 3a, Additional file 11: Figure S1). Colony shapes were generally round having smooth borders without bacterial extensions on $0.3 \%$ agar plates and formed branching structures at $15{ }^{\circ} \mathrm{C}$. Edge morphology of $\mathrm{Xcc}$ colonies at different temperatures was studied under inverted microscopes (Fig. 3b). The shape of colonies and direction of motion revealed that Xcc presented an outward protrusion at $15{ }^{\circ} \mathrm{C}$. Formation of an uneven and indefinite boundary at low temperature was also observed under the microscope (Fig. 3c). This implies a unique way of $X c c$ to adapt in low temperature environment.

\section{Low temperature modulates UFAs of Xcc}

In response to low temperatures, bacteria adjust membrane fatty acid composition to maintain membrane fluidity [13]. This might be dependent on whether the bacterial fatty acids are dominated by a mixture of straight-chain saturated fatty acids (SCFAs) and straight-chain unsaturated fatty acids (SCUFAs) or branch-chain saturated fatty acids (BCFAs). In many Gram-negative and some Grampositive species, liquidity is mainly altered by changing the ratio of SCFAs to SCUFAs [30]. In order to maintain the membrane fluidity within optimal range of biological activities, lipid desaturases convert saturated fatty acids into unsaturated fatty acids or synthesize unsaturated fatty acids to increase lipid metabolism at low temperatures
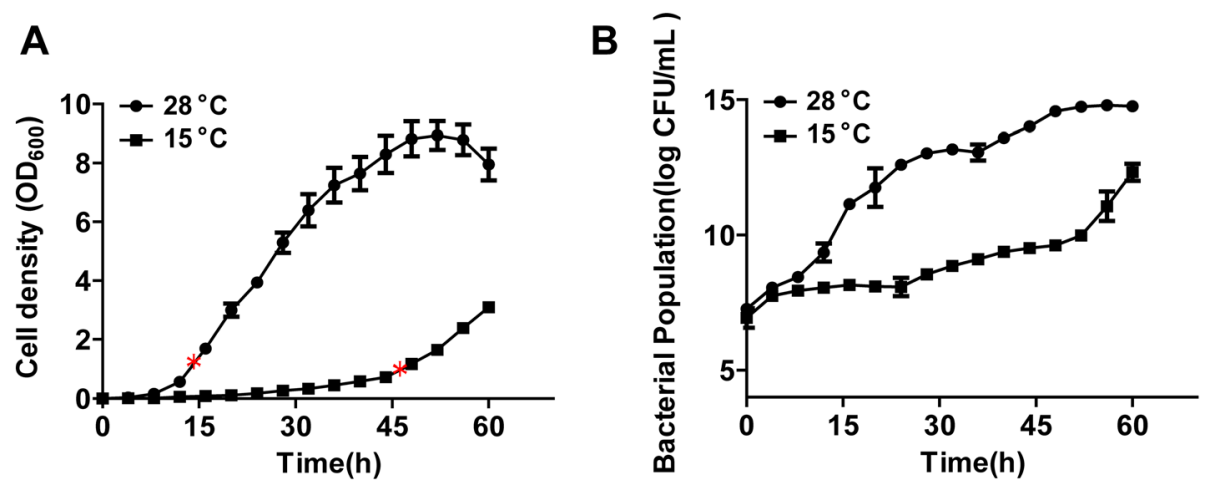

Fig. 1 Reduced Xcc strain growth at low temperatures. a Growth curves of bacterial strains in rich YEB medium at $28^{\circ} \mathrm{C}$ and $15^{\circ} \mathrm{C}$. "* indicates the growth stage in which RNA extraction was performed. $\mathbf{b}$ Colony forming units (CFU) of Xcc strains during different growth phases at $15^{\circ} \mathrm{C}$ and $28^{\circ} \mathrm{C}$. Error bars mean \pm standard deviation $(n=3)$. All experiments were repeated three times with similar results 


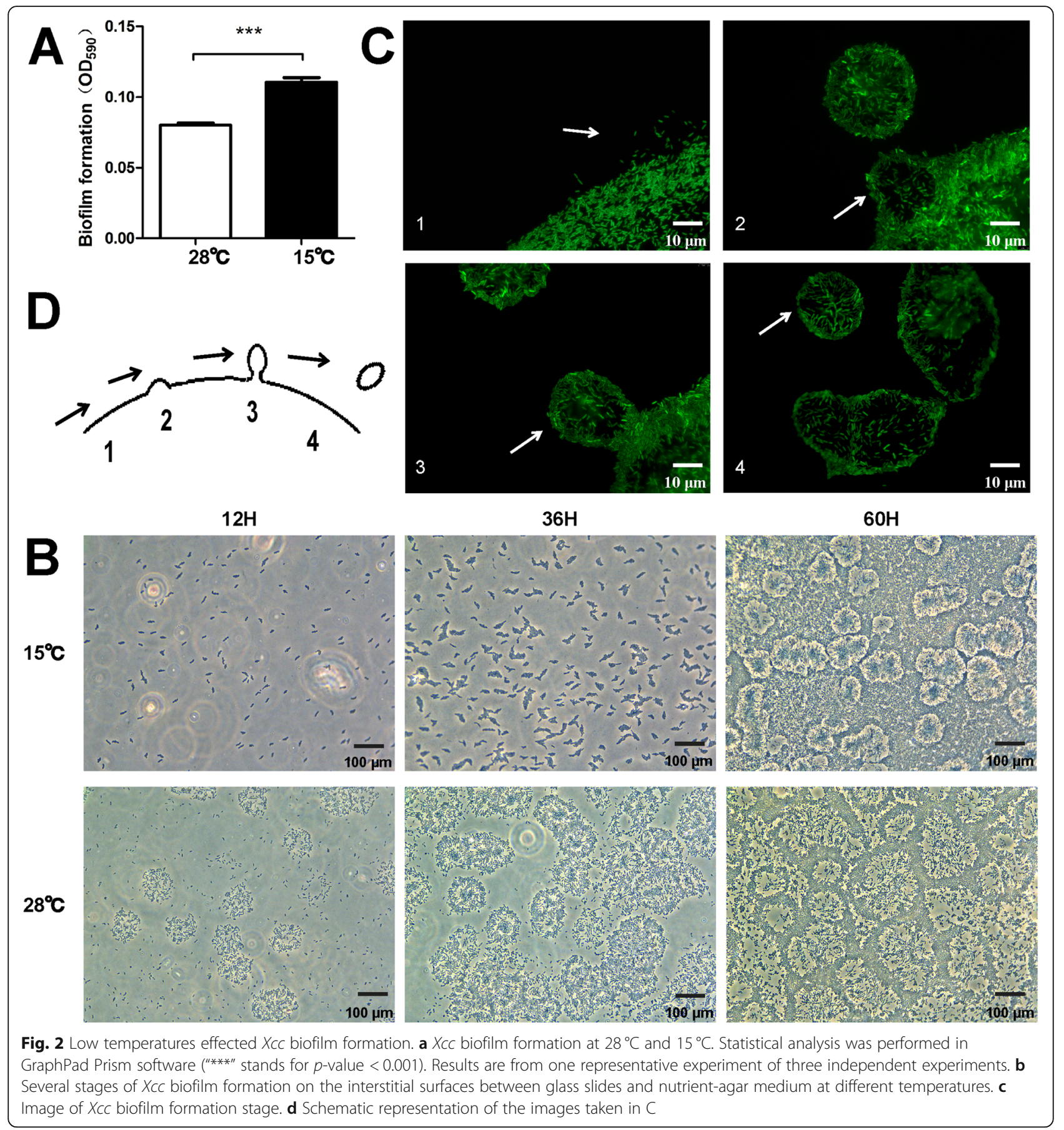

[31-34]. Species with a high proportion of BCFAs alter chain length and ratio of anteiso to iso fatty acids in response to low temperatures [35]. Little is known about the FA composition of Xcc at low temperatures. GC-MS analysis was conducted to find fatty acid composition of total lipid extracts of $X c c$, grown in YEB medium at $28^{\circ} \mathrm{C}$ and $15^{\circ} \mathrm{C}$. Pathogens were treated in the same state $\left(\mathrm{OD}_{600}=\right.$ 0.8 ) at different temperatures. As shown in Table 1, major $X c c$ fatty acids at $28^{\circ} \mathrm{C}$ included iso- $\mathrm{C}_{15: 0}(26.82 \%), \mathrm{n}-\mathrm{C}_{16: 1}$ cis-9 (16.56\%) and anteiso- $\mathrm{C}_{15: 0}(11.90 \%)$. Proportion of unsaturated fatty acids increased with the decrease in growth temperature, mainly due to the change in n$\mathrm{C}_{16: 1 \text { cis-9 }}$ percentage (Fig. 4). Growth at low temperature resulted in the decrease of iso- $\mathrm{C}_{15: 0}$ percentage and increased percentage of anteiso to iso fatty acids ratio (Fig. 4). These results appeared consistent with the changes in membrane phospholipids for adapting to low temperature environment [36]. 
A
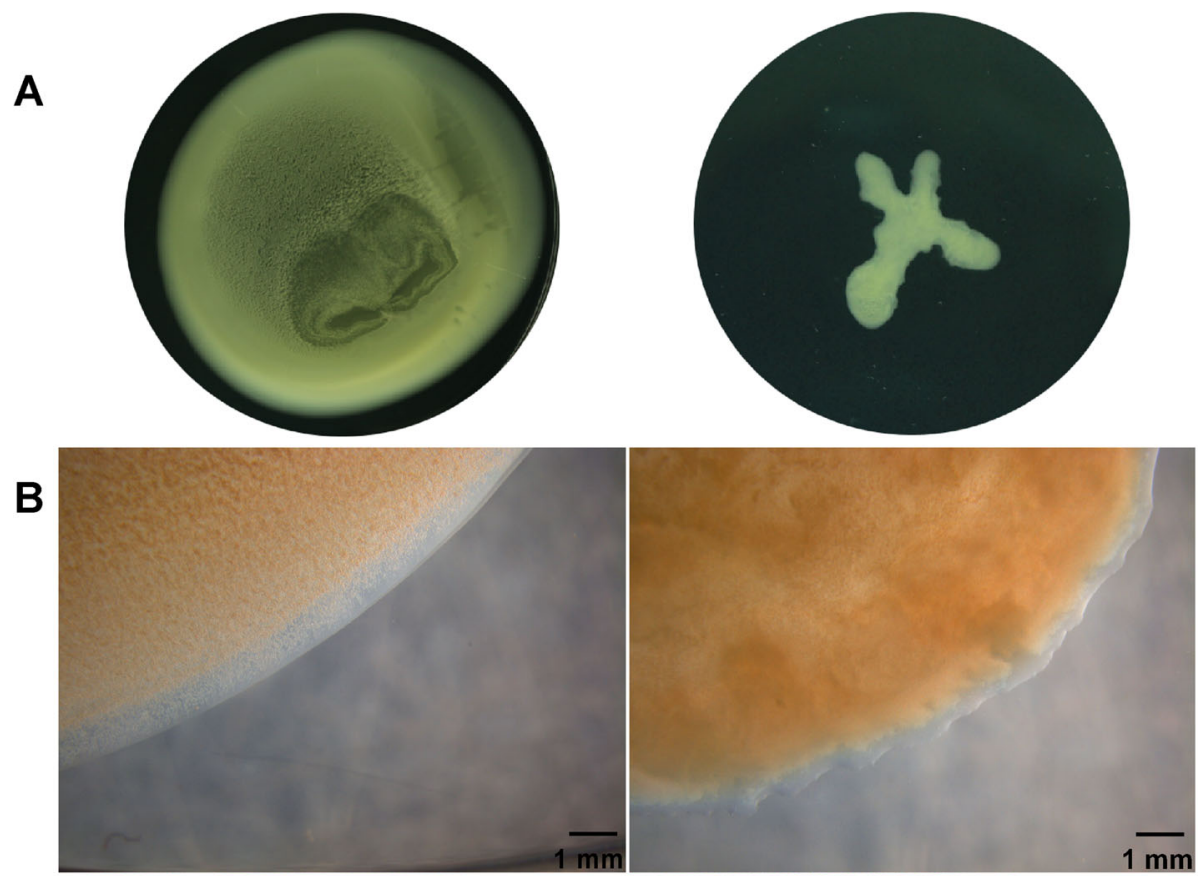

C

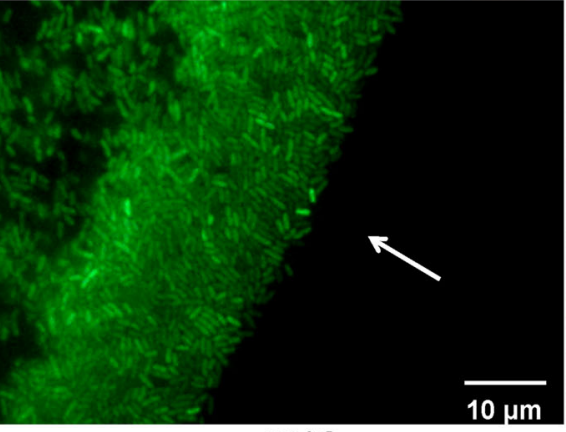

$28^{\circ} \mathrm{C}$

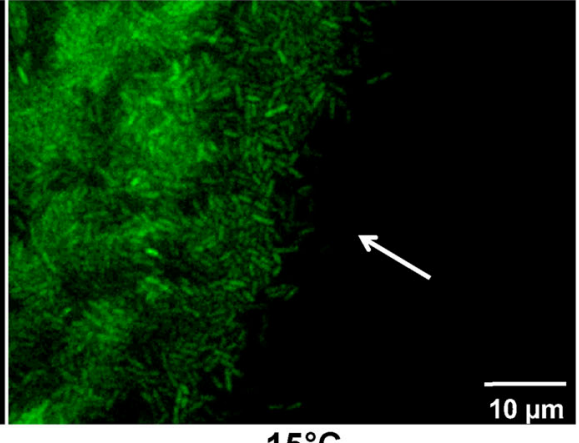

$15^{\circ} \mathrm{C}$

Fig. 3 Low temperatures effected Xcc swarming motility. a Swarming motility of Xcc wild- type strain on rich YEB medium plates at $28^{\circ} \mathrm{C}$ and $15^{\circ} \mathrm{C}$ after 3 days. $\mathbf{b}$ The characteristic image of Xcc colonies edge morphology were captured by inverted microscope at $28^{\circ} \mathrm{C}$ and $15^{\circ} \mathrm{C}$. $\mathbf{C}$ Microscopic images of Xcc edge expressing green fluorescent protein. Images were obtained under an inverted fluorescence microscope at 100X magnification

\section{Low temperature regulates the expression of genes} involved in several functional categories

In order to investigate the effect of low temperature on $X c c$, RNA-Seq of Xcc was carried out at different temperatures. A total of 286.19 million and 288.68 million reads were generated from $X c c$ grown at $28^{\circ} \mathrm{C}$ and $15^{\circ} \mathrm{C}$, respectively. The Q20 value of $X c c$ grown at $28^{\circ} \mathrm{C}$ and $15{ }^{\circ} \mathrm{C}$ remained as 96.69 and $96.97 \%$, respectively whereas the genome of $\mathrm{Xcc}$ was used as reference ( $\mathrm{NC}_{-}$ 003919.1) [37]. Similar to the reference strain, the GC content of $28^{\circ} \mathrm{C}$ and $15^{\circ} \mathrm{C}$ samples was 65.06 and $63.25 \%$. Clean reads were mapped to this genome at a ratio of 93.95 and $95.94 \%$ and approximately 83.45 $84.60 \%$ of the total mapped reads were unique alignments for $X c c$ grown at $28{ }^{\circ} \mathrm{C}$ and $15^{\circ} \mathrm{C}$. Multi-aligned reads were removed and only unique reads were used for further analysis (Additional file 2: Table S2). Twelve genes identified in transcriptomic analysis were selected to further confirm differentially expressed genes (DEGs) with qRT-PCR. Expression trend of qRT-PCR analysis was consistent with RNA-Seq data (Fig. 5) and results indicated acceptable quality of Xcc RNA sequencing.

To further explore the genes in response to low temperature, gene expressions were compared before and after low temperature treatments at a genome-wide level. A total of 2608 differentially expressed genes $\left(D^{2} G_{S}\right)$ were identified at different temperatures of which 389 upregulated and 2219 down-regulated (Additional file 3: Table S3). Based on this information, GO (Gene Ontology) annotation was carried out to classify the possible functions of $\mathrm{DEG}_{\mathrm{S}}$ [38] and top 5 enriched GO terms of each category were determined (Fig. 6b, c, d). Top three 
Table 1 Compositions of Xcc fatty acid phospholipids at different temperatures

\begin{tabular}{|c|c|c|}
\hline Fatty acid (\%) & $28^{\circ} \mathrm{C}$ & $15^{\circ} \mathrm{C}$ \\
\hline$n-C_{12: 0}$ & $0.97 \pm 0.20$ & $0.97 \pm 0.20$ \\
\hline$n-C_{11: 0} 3-O H$ & $1.94 \pm 0.25$ & $0.99 \pm 0.30$ \\
\hline$n-C_{14: 0} 3-O H$ & $3.53 \pm 0.30$ & $5.36 \pm 1.00$ \\
\hline iso- $\mathrm{C}_{14: 0}$ & $0.83 \pm 0.05$ & $0.73 \pm 0.10$ \\
\hline$n-C_{14: 0}$ & $2.10 \pm 0.20$ & $1.30 \pm 0.10$ \\
\hline$n-C_{16: 0} 3-O H$ & $5.38 \pm 0.40$ & $3.14 \pm 0.50$ \\
\hline iso- $\mathrm{C}_{15: 0}$ & $26.82 \pm 2.50$ & $14.30 \pm 1.00$ \\
\hline anteiso- $C_{15: 0}$ & $11.90 \pm 2.00$ & $13.71 \pm 2.00$ \\
\hline$n-C_{15: 0}$ & $4.23 \pm 0.50$ & $9.00 \pm 0.05$ \\
\hline iso- $C_{16: 0}$ & $2.25 \pm 0.40$ & $3.78 \pm 0.20$ \\
\hline$n-C_{16: 1} c i s-9$ & $16.56 \pm 2.50$ & $23.15 \pm 2.00$ \\
\hline$n-C_{16: 0}$ & $6.87 \pm 0.50$ & $7.04 \pm 1.00$ \\
\hline $\mathrm{n}-\mathrm{C}_{17: 1}$ cis-9 & $6.07 \pm 1.00$ & $4.29 \pm 1.00$ \\
\hline iso- $\mathrm{C}_{17: 0}$ & $3.31 \pm 0.50$ & $3.95 \pm 0.50$ \\
\hline anteiso- $\mathrm{C}_{17: 0}$ & $0.51 \pm 0.15$ & $0.91 \pm 0.20$ \\
\hline$n-C_{17: 1}$ cis-10 & $1.00 \pm 0.15$ & $2.55 \pm 0.08$ \\
\hline $\mathrm{n}-\mathrm{C}_{18: 1} \mathrm{cis}-11$ & $2.93 \pm 0.20$ & $2.24 \pm 1.50$ \\
\hline $\mathrm{n}-\mathrm{C}_{18: 1}$ trans-11 & $1.23 \pm 0.20$ & $1.59 \pm 0.55$ \\
\hline$n-C_{18: 0}$ & $1.57 \pm 0.15$ & $1.00 \pm 0.75$ \\
\hline
\end{tabular}

${ }^{a}$ Cells were grown in YEB medium for $36 \mathrm{~h}$ at $28^{\circ} \mathrm{C}$ or $15^{\circ} \mathrm{C}$. Total lipids were extracted and transesterified to fatty acid methyl esters and products were identified by GC-MS. Values represent percentages of total fatty acids and are means \pm standard deviations of three independent experiments. $b \mathrm{n}-\mathrm{C} 14: 03-$ $\mathrm{OH}$, 3-hydroxyltetradecanoic; iso-C15:0, 13-methyl-tetradecanoic acid; anteisoC15:0, 12-methyl-tetradecanoic acid; n-C15:0,pentadecanoic acid; iso-C16:0, 14methyl-pentadecanoic acid; $\mathrm{n}-\mathrm{C} 16: 1$ cis-9, cis-9-hexadecenoic acid; n-C16:0, hexadecanoic acid; iso-C17:1 cis-9, cis-9-15-methyl-hexadecenoic acid; isoC17:0, 15-methyl-hexadecanoic acid; anteiso-C17:0, 14-methyl-hexadecanoic acid; n-C17:0 cyclo, 9,10-methylene hexadecanoic acid; n-C18:1, cis-11-

octadecenoic acid; n-C18:0, octadecanoic acid

GO terms of classified genes were membrane (659), membrane part (573) and integral component of membrane (571) for cell component category; receptor activity (99), sequence-specific DNA binding transcription factor activity (70) and nucleic acid binding transcription factor activity (70) for molecular function and transport (265), localization (266) and establishment of localization (270) for biological processes. In order to understand the biological function of DEGs, pathway enrichment analysis was performed at KEGG database to classify DEGs into 151 KEGG pathways and top 5 enriched pathways are presented in Fig. 6a. Three enriched pathways mostly affected by temperature include homologous recombination, one carbon pool by folate and ribosome.

\section{Response of $X c c$ genes involved in carbon and nitrogen metabolism at low temperature}

Due to the effect of low temperature on Xcc growth (Fig. 1), DEGs involved in basal metabolism were further analyzed. Results of Xcc carbon metabolism at

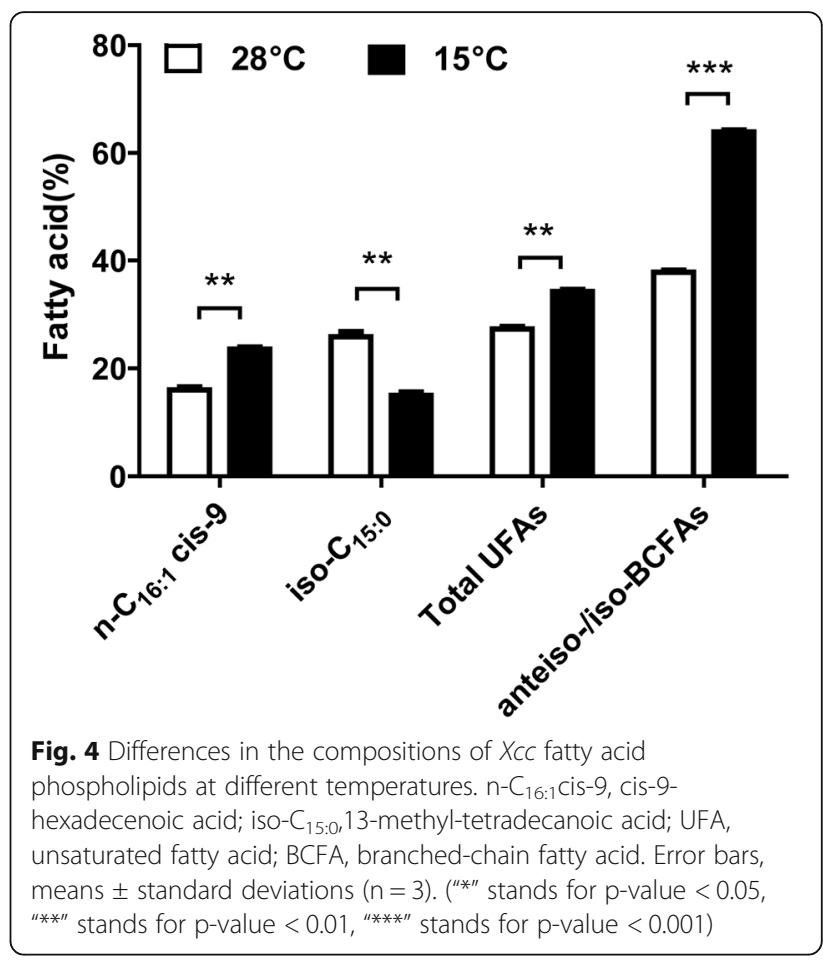

low temperature revealed that $90.7 \%$ genes, mainly involved in carbon and central carbon metabolism were down-regulated (Additional file 3: Table S3). Genes that encode enzyme catalyzing key chemical reactions for cell survival such as glucokinase, a-type carbonic anhydrase and bifunctional isocitrate dehydrogenase kinase/ phosphatase were down-regulated. Five genes involved in the glycolysis pathway and pyruvic acid metabolism were up-regulated indicating that low temperature does not inhibit their activities (Additional file 4: Table S4). These results demonstrated that low temperature might block other pathways to limit energy for cell growth and metabolism. Analysis of DEGs involved in nitrogen metabolism revealed that $79.2 \%$ genes mainly including the components of cellular nitrogen compound biosynthetic process were down-regulated (Additional file 5: Table S5). Genes involved in nitrogen compound transport were simultaneously down-regulated resulting in the reduction of nitrogen absorption. Overall, results suggest that low temperature disrupts carbon and nitrogen metabolism in Xcc.

Low temperature alters genes expression of flagellar and type IV pilus systems in Xcc

Significant differences in Xcc motility at different temperatures were observed (Fig. 2b, c). To further understand phenomenon at molecular level, DEGs associated with the flagellar system were analyzed. As expected, low temperature affected flagella assembly however varied effects of temperature on Xcc flagella assembly genes were observed (Additional file 6: Table S6). Low 


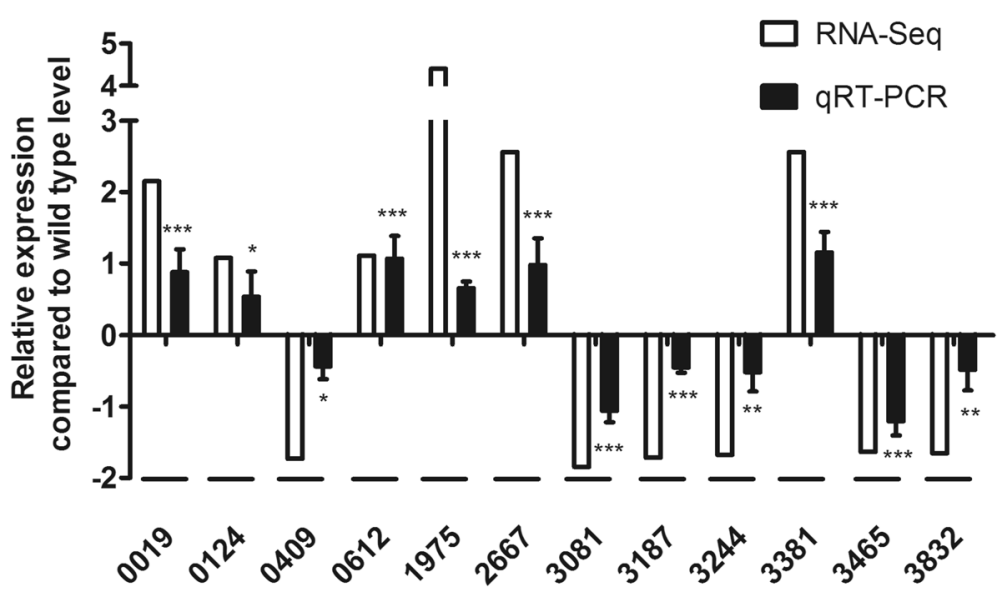

Fig. 5 qRT-PCR analysis of 12 DEGs identified by RNA-Seq and compared between $28^{\circ} \mathrm{C}$ and $15^{\circ} \mathrm{C}$. Y-axis indicates, relative expression to log 2 fold change (log2FC), X-axis indicates selected candidate genes of DEGs. Error bars, means \pm standard deviations $(n=3)$. Statistical analysis was performed between log2 fold change of qPCR experiment and 0. ("*" stands for p-value $<0.05$, "***" stands for p-value $<0.01$, "***" stands for p-value $<0.001)$

temperature treatment resulted in up-regulation of four genes and down-regulation of two genes suggesting that low temperature may disrupt flagella assembly of Xcc. Surprisingly type IV pilus systems, normally involved in bacterial cell adhesion to host cells and in bacterial cell motility [39], also responded to low temperature condition (Additional file 7: Table S7). The up-regulation of type IV pilus genes indicate their adaptation process to environmental pressure. To assess whether these changes in gene expression generate a temperature related motility phenotype in $X c c$, the twitching motility pattern of this bacterium at $15^{\circ} \mathrm{C}$ and $28^{\circ} \mathrm{C}$ were tested. Microscopic analysis of twitching assay at low temperature depicted that multicellular organization at the edges of subsurface twitching zones of Xcc cells has blurred and irregular boundary lines (Fig. 7a, b). Taken together, results suggest that low temperature may disrupt flagella assembly and upregulate type IV pilus genes expression leading to differential motility in $X c c$.

\section{Membrane lipid metabolism-related genes are predominately down-regulated at low temperature Xcc treatment}

Coordinated regulation of fatty acid biosynthesis is part of the normal bacterial response to environmental temperature changes (Table 1). As low temperature influenced UFAs, DEGs related to fatty acid biosynthesis, phospholipid synthesis and lipid A synthesis were analyzed (Fig. 8). At low temperature, 64 DEGs related to membrane lipid metabolism (Additional file 8: Table S8) and 88.9\% genes were down-regulated. Results further demonstrated that change in the temperature affects membrane lipid metabolism related genes in Xcc. Thereby, changing the membrane phospholipid component of $X c c$ to adapt in low temperature environment.
Specifically, 3-hydroxylacyl-ACP dehydratase/isomerase (FabA) and 3-ketoacyl-ACP synthase I (FabB) were not significantly up-regulated. The $f a b B$ and $f a b A$ genes encode key enzymes of classic anaerobic pathway of unsaturated fatty acid synthesis $[40,41]$. Thus FabA and FabB may not essentially increase the synthesis of unsaturated fatty acids. However, long-chain fatty acid transport protein (FadL) was up-regulated, implying that more free fatty acid can be transferred from outside into the cells. These results strongly suggest that different temperatures affect the gene expressions related to membrane lipid metabolism that changes membrane phospholipid components in Xcc.

\section{Pathogenesis-associated genes in Xcc are negatively regulated by low temperature}

This study explains that temperature change can affect bacterial virulence in Arabidopsis [4] and multiple cellular processes in Xcc (Fig. 6).Therefore, we analyzed the effect of low temperature on pathogenesis-associated genes expression in Xcc. Six pathogenesis related DEGs were influenced by low temperature treatment of whichone was up-regulated and 5 were down-regulated (Additional file 9: Table S9). Moreover, we further analyzed the genes related to pathogenesis secretion systems, which secrete degradation enzymes and toxins including type II (T2SS), type III (T3SS) and type IV (T4SS) secretion system. Results showed that $78.3 \%$ of genes related to these systems were down-regulated at low temperature (Additional file 10: Table S10). However, the expression of pathogenesis-associated genes was detected in rich medium, which might be different in other environments. 


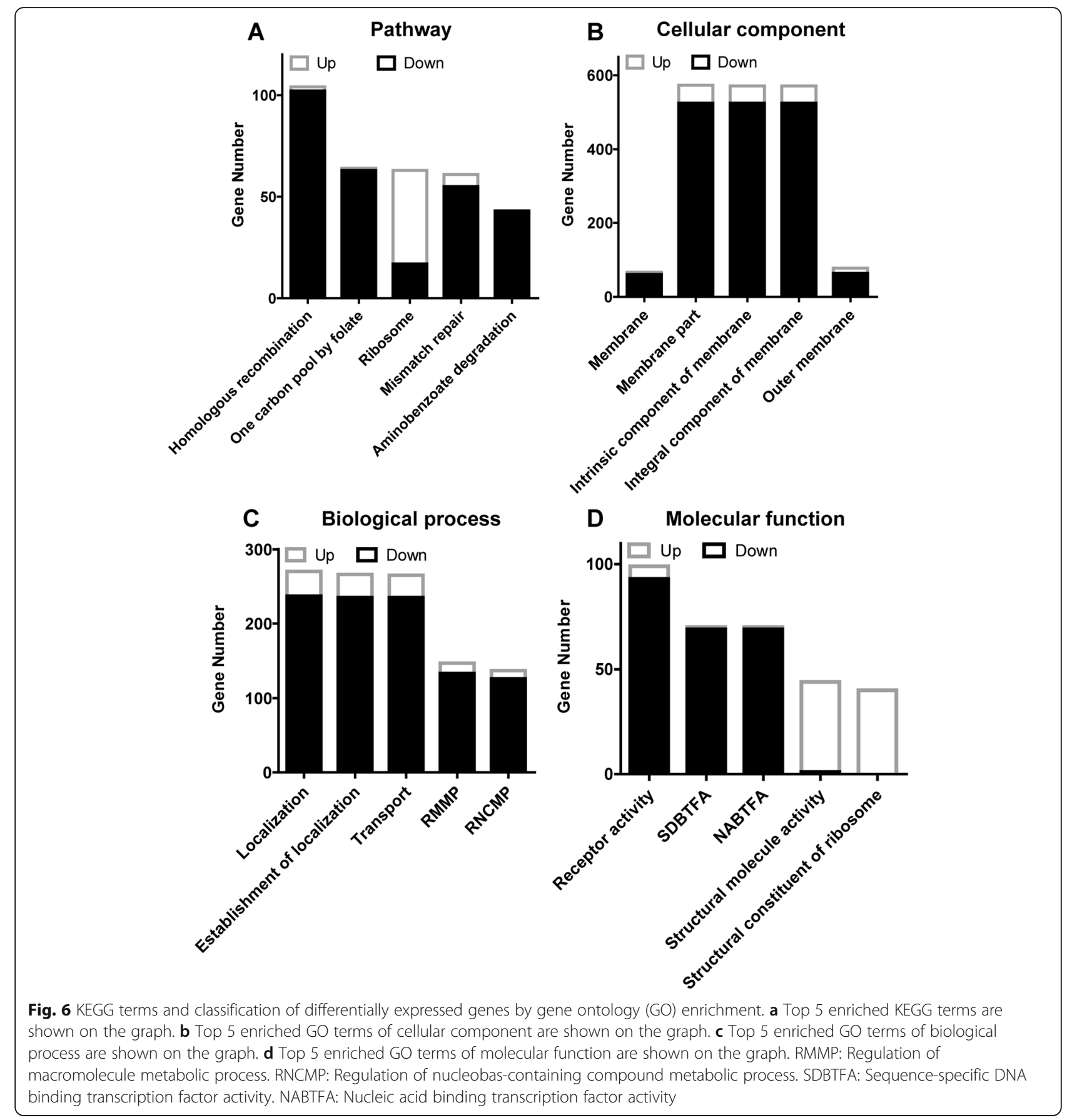

\section{Discussion}

Xanthomonas citri pv. citri is a global pathogen of citrus plants, which directly reduces fruit quality and quantity. Environmental factors play important role in determining the outcome of plant-pathogen interactions and development of plant disease [42]. Low temperature is a common environmental factor and cold shock is known to restrict bacterial growth [43]. During the study we observed significantly effected Xcc growth rate at low temperature (Fig. 1). Transcriptomic analyses showed that low temperature down-regulated expression of genes involved in carbon and nitrogen metabolism but had little effect on genes related to glycolysis pathway and pyruvic acid metabolism (Additional file 3: Table S3, Additional file 4: Table S4). Contrarily, ribosomal pathway was up-regulated (Fig. 6a) implying that ribosomal proteins might have special functions at low temperature like other bacteria [44]. Based on global gene expression analysis we proposed metabolic pathways associated with the effects of temperature changes on Xcc growth. 

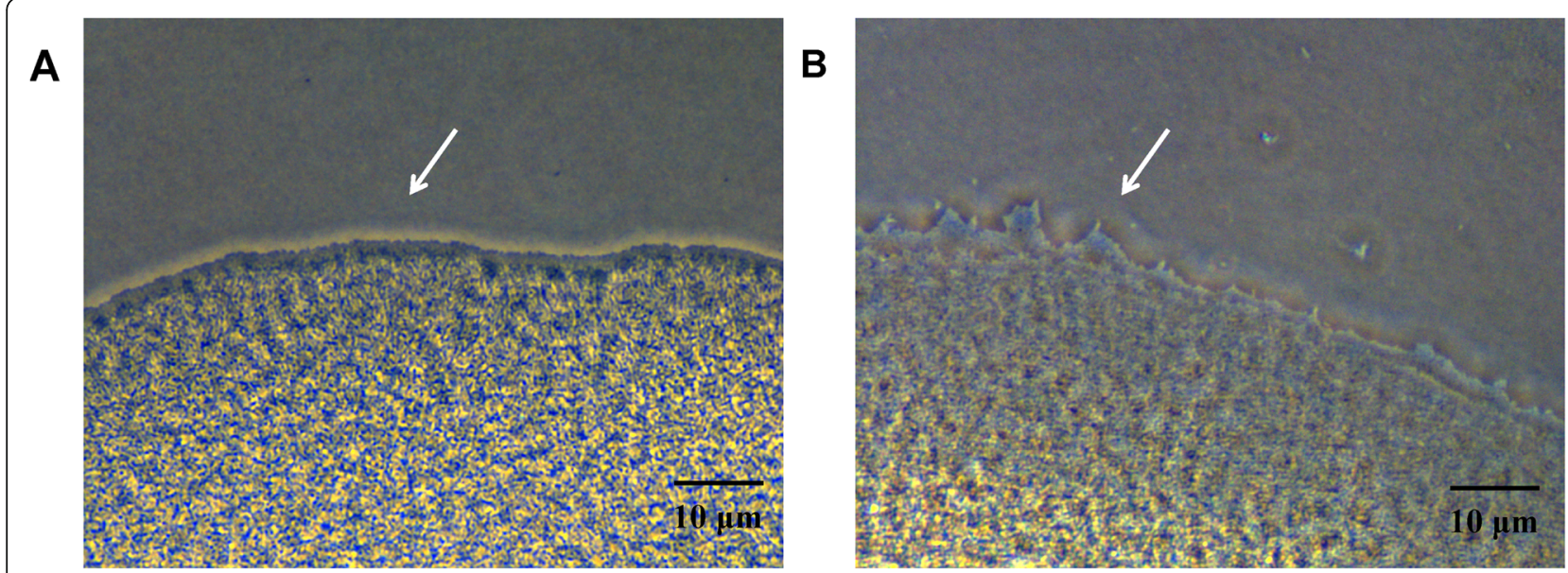

Fig. 7 Low temperatures effected Xcc twitching motility. a Microanalysis of multi-cellular organization at the edges of twitching zones of Xcc cells at $28^{\circ} \mathrm{C}$. $\mathbf{b}$ Microanalysis of the multi-cellular organization at the edges of twitching zones of Xcc cells at $15^{\circ} \mathrm{C}$. Images were obtained under an inverted microscope at 40X magnification. All experiments were repeated three times with similar results

Biofilms are strongly associated with pathogenesis. The persistence of $P$. aeruginosa in chronic lung infections of cystic fibrosis patients is related to biofilm formation, which enhances bacterial adhesion to the cell and evasion of host's immune responses. Biofilm formation also facilitates antibiotic tolerance and limits eradication [45]. Similar to Vibrio cholerae, Xcc formed more and tighter biofilms at low temperature (Fig. 2b) that demonstrates a regulatory switch between planktonic growth and biofilm formation in response to environmental changes [46]. Moreover, typical late autumn temperature $\left(15^{\circ} \mathrm{C}\right)$ implies [25] that increased biofilm formation represents bacterial preparation for overwintering. At low temperature motility was significantly influenced and Xcc formed an uneven and indefinite colony boundary (Fig. 3b, c). Motility plays a vital role in the attachment and colonization of bacteria in appropriate locations at favorable times [27, 47]. Transcriptome analysis revealed diverse effects of low temperature on Xcc flagella assembly genes (Additional file 6: Table S6). Results suggested that low temperature could be disruptive to flagellar system and subsequently disorganizes flagellar assembly. Interestingly, low temperature stimulated the expression of genes related to type IV pilus systems (Additional file 6: Table S6). Microscopic analysis of twitching assays depicted that subsurface twitching zones of Xcc cells have blurred and irregular boundary lines at low temperatures (Fig. 7a, b). This is an uncharacterized aspect of Xcc and underlying mechanism is the focus of our studies. Moreover, type IV pilus participates in biofilm formation $[48,49]$ and that might be a potential pathway of $X c c$ to increase biofilm formation at low temperatures.

Membrane fluidity is essential for the survival of bacteria at low temperature [30] and bacteria have evolved various strategies to modulate membrane fluidity [50-53]. This study revealed that low temperature stimulates the biosynthesis of unsaturated fatty acids by increasing the percentage of $n-C_{16: 1}$ cis-9 (Fig. 4). Further analysis indicated that increase in the proportion of unsaturated fatty acids might be due to overall change in the level of membrane phospholipid synthesis without involving FabA-FabB pathway. Lower growth temperature sharply reduced iso$\mathrm{C}_{15: 0}$ percentage and increased the ratio of anteiso to iso fatty acids (Fig. 4). It is an effective way to adjust the membrane fluidity for adapting at low temperature. However, $X c c$ mechanism of altering the ratio of anteiso to iso fatty acids at low temperature is unknown. Nevertheless, effect of temperature on the gene expression of $\mathrm{FabH}$ (XAC1964, XAC2571 and XAC1123) was noted (Fig. 8). FabH plays an important role in branched-chain fatty acids and carries out first condensation reaction in fatty acid biosynthesis pathway by using a variety of substrates [30, 54-57]. This might be a potential mechanism to alter the ratio of branched-chain fatty acids at low temperature through the selection of substrates. However, FabH pathway requires further investigation. Analysis of the genes related to phospholipid synthesis and lipid A synthesis in DEGs (Fig. 8) revealed that $88.9 \%$ genes were downregulated (Additional file 8: Table S8) implying that more energy is used for basal metabolism of bacteria at low temperature.

Virulence gene expression in pathogenic bacteria is regulated by environmental parameters and temperature is the key factor [58]. Studies have shown that most plant pathogen virulence genes exhibit increased transcription below optimum temperatures [59]. However, we found that a large portion of genes related to Xcc pathogenesis were down-regulated at low temperature (Additional file 8: Table S8), including CRP-like protein 


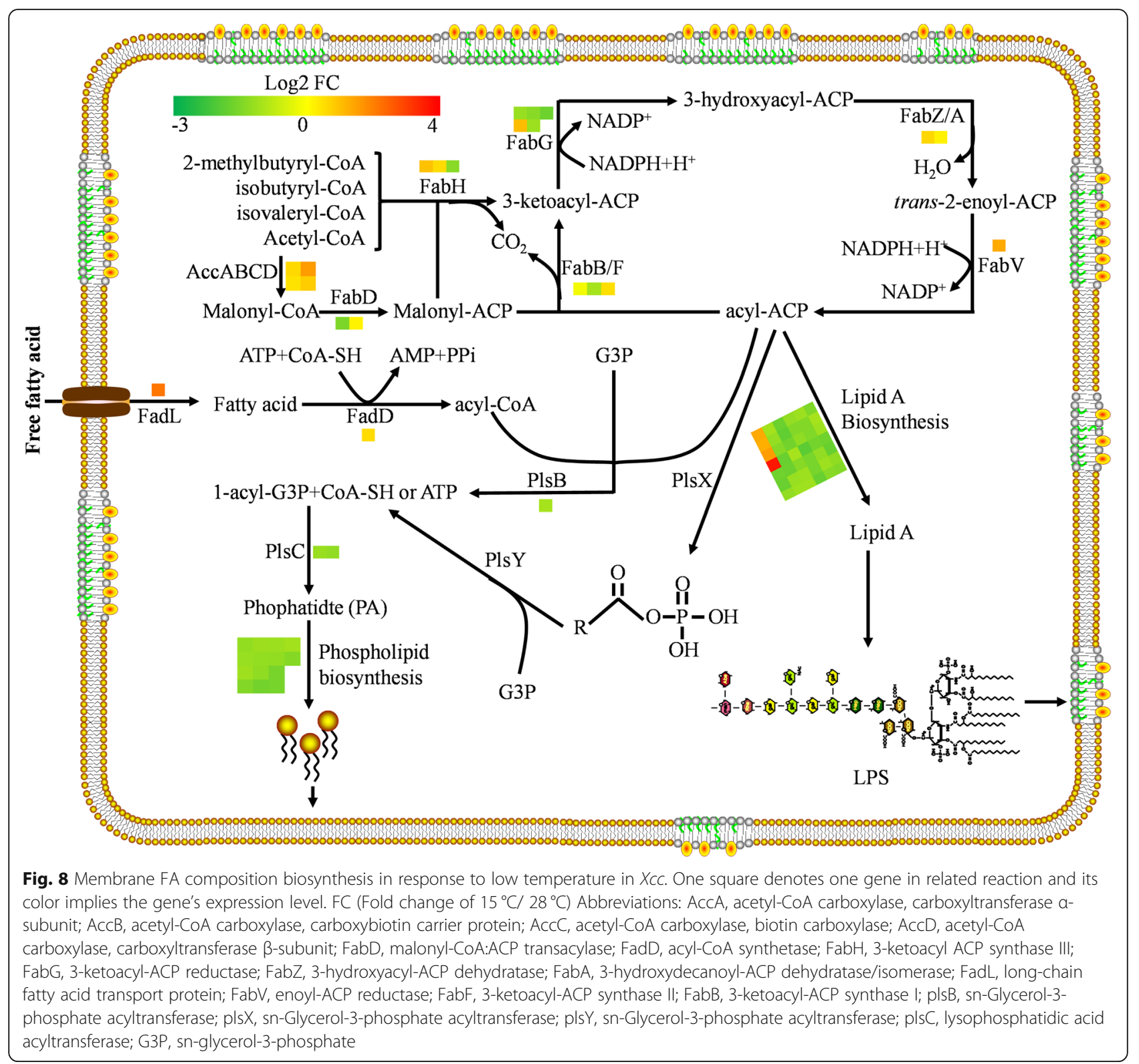

Clp, adhesin, membrane protein, avirulence protein and EscJ/YscJ/HrcJ family type III secretion inner membrane ring protein. This might be a self-protective mechanism in bacteria as virulence factors are essential for the infection process only but not necessary under environmental stress. To ensure their survival, bacteria do not express virulence genes to save energy. Consistent with $P$. syringae, we found that low temperature influenced Xcc secretion system that might reduce the injection of effector proteins or toxins into host cells (Additional file 10: Table S10) [60]. Further investigation is required to elaborate this interesting observation. However, YEB medium used in this study is a rich medium that is not generally associated with pathogenicity inducing conditions. In future we will consider using different medium to mimic plant's internal environment. Meanwhile, we speculate that low temperature may initiate additional uncharacterized mechanisms to control $X c c$ virulence.

\section{Conclusions}

In short, physiological characteristics of $X c c$ at low temperature were examined and genome wide transcriptional analysis presented specific response of $X c c$ at low temperature. Results suggested that many biological processes participate to respond at low temperature including carbon, nitrogen and fatty acid metabolism. In addition, low temperatures influence motility, biofilm formation and expression of pathogenicity related genes. Data of this study provide insights into molecular mechanisms of $X c c$ to adapt at low temperature and present 
an experimental reference information for future research to control plant diseases by temperaturedependent strategies.

\section{Methods}

\section{Bacterial strains, media cultures and growth conditions}

Xanthomonas citri pv. citri was grown at $28^{\circ} \mathrm{C}$ and $15^{\circ} \mathrm{C}$ in YEB medium ( $10 \mathrm{~g} / \mathrm{L}$ peptone, $5 \mathrm{~g} / \mathrm{L}$ yeast extract, $5 \mathrm{~g} /$ $\mathrm{L} \mathrm{NaCl}, 5 \mathrm{~g} / \mathrm{L}$ sucrose, $0.25 \mathrm{~g} / \mathrm{LMgSO}_{4}, \mathrm{pH} 7.0$ ) on a rotary shaker $(180 \mathrm{rpm})$. Bacterial growth in liquid medium at $28^{\circ} \mathrm{C}$ and $15^{\circ} \mathrm{C}$ was determined by measuring optical density at $600 \mathrm{~nm}\left(\mathrm{OD}_{600}\right)$ and plating colony forming units (CFU). Briefly, Xcc strains were cultured overnight and then inoculated into fresh YEB medium. Strains were cultured at $28^{\circ} \mathrm{C}$ and $15^{\circ} \mathrm{C}$ at $200 \mathrm{rpm}$. Every $4 \mathrm{~h}$, 1 - $\mathrm{mL}$ of each culture was collected to measure the optical density at $600 \mathrm{~nm}\left(\mathrm{OD}_{600}\right)$ and estimate bacterial CFU by dilution plate counting. Three replicates were performed for each strain and bacterial growth curves were plotted according to average values.

\section{Swarming motility assay}

Swarming motility assays were performed in YEB medium plates supplemented with $0.3 \%$ agarose. Bacteria were inoculated in the center of plates and incubated at $28^{\circ} \mathrm{C}$ and $15^{\circ} \mathrm{C}$ for 3 days before assessment. To conduct microscopic analysis of motility assays, $X c c$ strains were inoculated through a thin layer of nutrient agar supplemented with $2 \mathrm{mM} \mathrm{CaCl}_{2}$ and incubated at $28^{\circ} \mathrm{C}$ for 2 days.

\section{Twitching motility assay}

Twitching motility assays were performed according to Dunger et al. (2014) [49]. For microscopic analysis of motility assays, Xcc strains were stabbed through YEB medium (1\% agar) supplemented with $2 \mathrm{mM} \mathrm{CaCl}_{2}$, covered with glass slides and statically incubated in a humidified chamber at $28^{\circ} \mathrm{C}$ for 2 days.

\section{Biofilm formation assay}

$X c c$ strains were grown in YEB to $\mathrm{OD}_{600}=1.0$, and inoculated into the 96-well plates for $36 \mathrm{~h}$ in rich YEB medium. Biofilms were rinsed three times with $d_{d d} \mathrm{H}_{2} \mathrm{O}$, treated with $0.3 \%$ crystal violet for $15 \mathrm{~min}$, again rinsed three times with $\mathrm{ddH}_{2} \mathrm{O}$ and re-suspended in 95\% ethanol. Biomass was read in spectrophotometer at $590 \mathrm{~nm}$. For microscopic analysis of biofilm formation assays, overnight cultures of $X c c$ strains expressing GFP in YEB medium were collected by centrifugation, washed with fresh medium and adjusted to $\mathrm{OD}_{600}=1.0$. Ten microlitre of this culture was diluted with $1 \mathrm{ml}$ YEB medium, transferred into a thin layer of nutrient agar, covered with glass slides and statically incubated in a humidified chamber at $28^{\circ} \mathrm{C}$. The pBBR1MCS-5-GFP plasmid were used to transform $X c c$ strains into expressing green fluorescent protein.

\section{Analysis of fatty acid composition}

To determine FA composition, $X c c$ strains were grown in YEB $\left(\mathrm{OD}_{600}=0.8\right)$ at $28^{\circ} \mathrm{C}$ and $15^{\circ} \mathrm{C}$. Fatty acid methyl esters were synthesized and extracted as previously described [61]. Cellular lipids were saponified by the addition of $1 \mathrm{~mL}$ sodium hydroxide/methanol solution at $100{ }^{\circ} \mathrm{C}$ and $800 \mathrm{rpm}$ for $40 \mathrm{~min}$. Fatty acids were methylated by the addition of $2 \mathrm{~mL}$ hydrochloric acid/methanol solution at $80^{\circ} \mathrm{C}$ for $30 \mathrm{~min}$ and cooled to below $20^{\circ} \mathrm{C}$. Fatty acid methylesters were obtained by three extractions with $1 \mathrm{~mL}$ petroleumether. Solvent was removed under a stream of nitrogen and residues were dissolved in $100 \mu \mathrm{L}$ of hexane. Crude extract was filtered through $0.22-\mu \mathrm{m}$ Mini-star units and $2 \mu \mathrm{L}$ extract was analyzed by gas chromatography-mass spectrometry (GC-MS system Agilent 5975c) with chromatographic column DB 5MS. Oven temperature was held at $100^{\circ} \mathrm{C}$ for $5 \mathrm{~min}$, changed at $10^{\circ} \mathrm{C} / \mathrm{min}$ to $200^{\circ} \mathrm{C}$ and held for $5 \mathrm{~min}$, then changed at $10^{\circ} \mathrm{C} / \mathrm{min}$ to $250^{\circ} \mathrm{C}$ and held for $5 \mathrm{~min}$. Electron impact ionization $\left(\mathrm{EI}^{+}, 70 \mathrm{eV}\right)$ was used for all samples. Mass spectrometry was carried out at $1 \mathrm{~s} / \mathrm{scan}, \mathrm{m} / \mathrm{z} 35-500,1$ $\mathrm{kV}$ and data were analyzed by NIST 08 database.

\section{Sample preparation for RNA sequencing and differential expression analysis}

$X$. citri strains were cultured on YEB medium at $28^{\circ} \mathrm{C}$ and $15^{\circ} \mathrm{C}$, and collected at $\mathrm{OD}_{600}$ of $1.0\left(4 \times 10^{9} \mathrm{CFU} /\right.$ $\mathrm{ml}$ ). Bacterial strains were centrifuged and pellet was washed with DEPC water. RNA was extracted from the collected cells with Bacterial RNA Extraction Kit (Vazyme, China) according to the manufacturer's instructions. RNA quality was checked in RNA-Nano (Agilent 2100) followed by RNA degradation and contamination verification on $1 \%$ agarose gel. Samples with RNA integrity number (RIN) more than 9 were used in downstream analysis. Clustering and sequencing were performed by Vazyme that employed spliced reads to determine exon connectivity. Gene FPKMs were computed by summing the FPKMs of transcripts in each gene group. FPKM stands for "fragments per of exon per million fragments mapped", and it is calculated based on the length of fragments and reads count mapped to each fragment. FPKM also considers the effect of sequencing depth and gene length on reads counts, and is currently the most commonly used method for estimating gene expression levels [62]. Cuffdiff (v1.3.0) was used to calculate FPKMs of coding genes in each sample [63]. Cuffdiff provides statistical routines for determining differential expression in digital transcript or gene expression datasets by using a model based on negative binomial distribution. Genes with corrected $p$ value less 
than 0.05 and absolute value of $\log 2$ (fold change) greater than or equal to 1 were assigned as significantly differentially expressed.

\section{Gene ontology and KEGG enrichment analysis}

Analysis was conducted by putting all the differentially expressed genes to the Gene Ontology (GO) database (http://www.geneontology.org/) of each term mapping and calculated the number of genes in each term. It was followed by hypergeometric inspection to find out comparison with the entire genome, significantly enriched in the differentially expressed genes GO entries. Pathway significant enrichment analysis was based on KEGG pathway that applies hypergeometric test to find the pathway of significant enrichment in differentially expressed genes compared with the whole genome. In general, Corrected $p$-value $<0.05$ indicated that differentially expressed genes were significantly enriched in KEGG pathway.

\section{Quantitative real-time PCR}

Cells were collected at cell optical density $\left(\mathrm{OD}_{600}\right)$ of 1.0 in YEB medium at $28{ }^{\circ} \mathrm{C}$ and $15^{\circ} \mathrm{C}$. Total RNA was extracted from at least two independent biological repeats by using Bacterial RNA Extraction Kit (Vazyme, China) according to the manufacturer's protocols. Reverse transcription PCR was performed using a HiScript ${ }^{\circ}$ II Q RT SuperMix for qPCR (+gDNA wiper) (Vazyme, China) according to the manufacturer's instructions. Primers used in this assay are listed in Additional file 1: Table S1. Quantification of gene expression and melting curve analysis was conducted in 7300Plus Real-Time PCR System (Thermo Scientific) by using ChamQ $^{\mathrm{mi}}$ Universal SYBR $^{\circ}$ qPCR Master Mix (Vazyme, China) according to the manufacturer's instructions. Quantitative RT-PCR analysis of $r p o B$ gene expression served as control. Relative expressions of target genes were calculated by following Quantitation-Comparative CT $(\Delta \Delta \mathrm{CT})$ method.

\section{Data analysis method}

Statistical analyses were performed with one-way ANOVA test in GraphPad. Values and error bars represent means and SD. “*” stands for p-value $<0.05$, “***" stands for p-value $<0.01$, “***”, stands for $\mathrm{p}$-value $<0.001$; ns stands for not significant.

\section{Supplementary information}

Supplementary information accompanies this paper at https://doi.org/10 1186/s12864-019-6193-0.

Additional file 1: Table S1. Primers used in qRT-PCR for validating differentially expressed genes.

Additional file 2: Table S2. Overview of the sequencing and assembly Additional file 3: Table S3. Differential gene expressions in XcC at $15^{\circ} \mathrm{C}$.
Additional file 4: Table S4. List of genes related to carbohydrate metabolic process in Xcc regulated by temperature.

Additional file 5: Table S5. List of genes related to cellular nitrogen compound biosynthetic process in Xcc regulated by temperature.

Additional file 6: Table S6. List of genes related to flagellum in Xcc regulated by temperature.

Additional file 7: Table S7. List of genes related to pilus organization in Xcc regulated by temperature.

Additional file 8: Table S8. List of genes related to fatty acid metabolism in Xcc regulated by temperature.

Additional file 9: Table S9. List of genes related to XcC pathogenesis regulated by temperature.

Additional file 10: Table S10. List of genes related to Xcc secretion regulated by temperature.

Additional file 11: Figure S1. Low temperatures effected Xcc swarming motility.

\section{Acknowledgements}

The authors would like to thank Dr. Stephen Ahator and Dr. Yihu Dong for the revision of this manuscript.

\section{Authors' contributions}

$J X L, K H L$ and CQC conceived and designed experiments. JXL, KHL, JPW and JRD carried out experiments. JXL, KHL, and QGL analyzed data and prepared figures. JXL and CQC wrote the manuscript. All authors read and approved the final manuscript.

\section{Funding}

Study was supported by the grants from National Key Project for Basic Research of China (973 Program number: 2015CB150600) and Science and Technology Planning Project of Guangdong Province (grant numbers: 2015A020209133). The funding body has no role in the design of this study, interpretation of data and writing of manuscript.

\section{Availability of data and materials}

RNA sequence dataset supporting the results of this article is available at NCBI under the bioproject no. PRJNA544888 with the Sequence Read Archive (SRA) accession no. SRP199587 (https://dataview.ncbi.nlm.nih.gov/ ?search=SUB5672622)

\section{Ethics approval and consent to participate}

Not applicable.

\section{Consent for publication}

Not applicable.

\section{Competing interests}

The authors declare that they have no competing interests.

Received: 17 February 2019 Accepted: 15 October 2019

Published online: 06 November 2019

\section{References}

1. Strange RN, Scott PR. Plant disease: a threat to global food security. Annu Rev Phytopathol. 2005;43:83-116.

2. Colhoun J. Effects of environmental factors on plant disease. Annu Rev Phytopathol. 1973;11:343-64.

3. Velásquez AC, Castroverde CDM, He SY. Plant-pathogen warfare under changing climate conditions. Curr Biol. 2018;28:R619-34.

4. Huot B, Castroverde CDM, Velásquez AC, Hubbard E, Pulman JA, Yao J, et al. Dual impact of elevated temperature on plant defence and bacterial virulence in Arabidopsis. Nat Commun. 2017;8:1808.

5. Chinnusamy V, Zhu J, Zhu J. Cold stress regulation of gene expression in plants. Trends Plant Sci. 2007;12:444-51.

6. Heidarvand L, Maali AR. What happens in plant molecular responses to cold stress? Acta Physiol Plant. 2010;32:419-31. 
7. Yamaguchi-Shinozaki K, Shinozaki K. Transcriptional regulatory networks in cellular responses and tolerance to dehydration and cold stresses. Annu Rev Plant Biol. 2006;57:781-803.

8. Chinnusamy V, Zhu J, Sunkar R. Gene regulation during cold stress acclimation in plants. Methods Mol Biol. 2010;639:39.

9. Zhu J, Dong C, Zhu J. Interplay between cold-responsive gene regulation, metabolism and RNA processing during plant cold acclimation. Curr Opin Plant Biol. 2007;10:290-5.

10. Miura K, Ohta M. SIZ1, a small ubiquitin-related modifier ligase, controls cold signaling through regulation of salicylic acid accumulation. J Plant Physiol. 2010;167:555-60.

11. Scott IM. Salicylate accumulation inhibits growth at chilling temperature in Arabidopsis. Plant Physiol. 2004;135:1040-9.

12. Komatsu S, Yang G, Khan M, Onodera H, Toki S, Yamaguchi M. Overexpression of calcium-dependent protein kinase 13 and calreticulin interacting protein 1 confers cold tolerance on rice plants. Mol Gen Genomics. 2007;277:713-23.

13. Annous BA, Becker LA, Bayles DO, Labeda DP, Wilkinson BJ. Critical role of anteiso- $C_{15.0}$ fatty acid in the growth of Listeria monocytogenes at low temperatures. Appl Environ Microbiol. 1997;63:3887-94.

14. Becker LA, Evans SN, Hutkins RW, Benson AK. Role of sigma(B) in adaptation of Listeria monocytogenes to growth at low temperature. J Bacteriol. 2000; 182:7083-7.

15. Cronan JE, Rock CO. Biosynthesis of membrane lipids. EcoSal Plus. 2008;3:144.

16. Beckering $\mathrm{CL}$, Steil L, Weber MH, Volker U, Marahiel MA. Genomewide transcriptional analysis of the cold shock response in Bacillus subtilis. J Bacteriol. 2002;184:6395-402.

17. Wada H, Murata N. Temperature-induced changes in the fatty acid composition of the cyanobacterium, Synechocystis PCC6803. Plant Physiol. 1990;92:1062-9.

18. Ermolenko DN, Makhatadze Gl. Bacterial cold-shock proteins. Cell Mol Life Sci. 2002;59:1902-13.

19. Majdalani N, Cunning C, Sledjeski D, Elliott T, Gottesman S. DsrA RNA regulates translation of RpoS message by an anti-antisense mechanism, independent of its action as an antisilencer of transcription. Proc Natl Acad Sci U S A. 1998;95:12462-7.

20. Goodchild A, Saunders NFW, Ertan H, Raftery M, Guilhaus M, Curmi PMG et al. A proteomic determination of cold adaptation in the Antarctic archaeon, Methanococcoides burtonii. Mol Microbiol. 2004;53:309-21.

21. Prakash JSS, Sinetova M, Zorina A, Kupriyanova E, Suzuki I, Murata N, et al. DNA supercoiling regulates the stress-inducible expression of genes in the cyanobacterium Synechocystis. Mol BioSyst. 2009;5:1904.

22. Ryan RP, Vorhölter F, Potnis N, Jones JB, Van Sluys M, Bogdanove AJ, et al. Pathogenomics of Xanthomonas: understanding bacterium-plant interactions. Nat Rev Microbiol. 2011;9:344-55.

23. Gottwald TR, Graham JH, Schubert TS. Citrus canker: the pathogen and its impact. Plant Health Progress. 2002;3:15.

24. Lv X, Zhao S, Ning Z, Zeng H, Shu Y, Tao O, et al. Citrus fruits as a treasure trove of active natural metabolites that potentially provide benefits for human health. Chem Cent J. 2015;9:68.

25. Duan H, Qian H, Li M, Du Y. Climatic suitability of citrus in subtropical China. J Appl Ecol. 2010:21:1915.

26. Paulick A, Jakovljevic V, Zhang S, Erickstad M, Groisman A, Meir Y, et al. Mechanism of bidirectional thermotaxis in Escherichia coli. Elife. 2017:6: e26607.

27. Kilmury SLN, Burrows LL. The Pseudomonas aeruginosa PilSR twocomponent system regulates both twitching and swimming motilities. Mbio. 2018;9:e1310-8.

28. Van Laar TA, Esani S, Birges TJ, Hazen B, Thomas JM, Rawat M. Pseudomonas aeruginosa gshA mutant is defective in biofilm formation, swarming, and pyocyanin production. mSphere. 2018;3:e118-55.

29. Malamud F, Torres PS, Roeschlin R, Rigano LA, Enrique R, Bonomi HR, et al. The Xanthomonas axonopodis pv citri flagellum is required for mature biofilm and canker development. Microbiology. 2011;157:819-29.

30. Zhang Y, Rock CO. Membrane lipid homeostasis in bacteria. Nat Rev Microbiol. 2008;6:222-33

31. Mendoza DD. Temperature sensing by membranes. Annu Rev Microbiol. 2014;68:101-16.

32. Nakamura MT, Nara TY. Structure, function, and dietary regulation of $\delta 6, \delta 5$, and $\delta 9$ desaturases. Annu Rev Nutr. 2004;24:345-76.
33. de Mendoza D, Cronan JE. Thermal regulation of membrane lipid fluidity in bacteria. Trends Biochem Sci. 1983:8:49-52.

34. Holthuis JCM, Menon AK. Lipid landscapes and pipelines in membrane homeostasis. Nature. 2014;510:48-57.

35. Suutari M, Laakso S. Microbial fatty acids and thermal adaptation. Crit Rev Microbiol. 2008:20:285-328.

36. Li K, Yu Y, Dong H, Zhang W, Ma J, Wang H. Biological functions of ilvC in branched-chain fatty acid synthesis and diffusible signal factor family production in Xanthomonas campestris. Front Microbiol. 2017;8:2486

37. Da Silva ACR, Ferro JA, Reinach FC, Farah CS, Furlan LR, Quaggio RB, et al. Comparison of the genomes of two Xanthomonas pathogens with differing host specificities. Nature. 2002;417:459-63.

38. Harris MA, Clark J, Ireland A, Lomax J, Ashburner M, Foulger R, et al. The gene ontology $(\mathrm{GO})$ database and informatics resource. Nucleic Acids Res. 2004:32:D258-61.

39. Wall D, Kaiser D. Type IV pili and cell motility. Mol Microbiol. 1999;32:1-10.

40. Wang H, Cronan JE. Functional replacement of the FabA and FabB proteins of Escherichia coli fatty acid synthesis by Enterococcus faecalis FabZ and FabF homologues. J Biol Chem. 2004;279:34489-95.

41. Feng Y, Cronan JE. Escherichia coli unsaturated fatty acid synthesis: complex transcription of the fabA gene and in vivo identification of the essential reaction catalyzed by FabB. J Biol Chem. 2009;284:29526-35.

42. Atkinson NJ, Urwin PE. The interaction of plant biotic and abiotic stresses: from genes to the field. J Exp Bot. 2012;63:3523-43.

43. Das HK, Goldstein A. Limited capacity for protein synthesis at zero degrees centigrade in Escherichia coli. J Mol Biol. 1968;31:209-26.

44. Jones PG, Mitta M, Kim Y, Jiang W, Inouye M. Cold shock induces a major ribosomal-associated protein that unwinds double-stranded RNA in Escherichia coli. Proc Natl Acad Sci U S A. 1996;93:76-80.

45. Vital-Lopez FG, Reifman J, Wallqvist A. Biofilm formation mechanisms of Pseudomonas aeruginosa predicted via genome-scale kinetic models of bacterial metabolism. PLoS Comput Biol. 2015:11:e1004452.

46. Townsley L, Yildiz FH. Temperature affects c-di-GMP signalling and biofilm formation inVibrio cholerae. Environ Microbiol. 2015;17:4290-305.

47. Nan B, Zusman DR. Novel mechanisms power bacterial gliding motility. Mol Microbiol. 2016;101:186-93.

48. O'Toole GA, Kolter R. Flagellar and twitching motility are necessary for Pseudomonas aeruginosa biofilm development. Mol Microbiol. 1998;30:295.

49. Dunger G, Guzzo CR, Andrade MO, Jones JB, Farah CS. Xanthomonas citri subsp.citri type IV pilus is required for twitching motility, biofilm development, and adherence. Mol Plant-Microbe Interact. 2014;27:1132-47.

50. Kiran MD, Prakash JSS, Annapoorni S, Dube S, Kusano T, Okuyama H, et al. Psychrophilic Pseudomonassyringae requires trans-monounsaturated fatty acid for growth at higher temperature. Extremophiles. 2004;8:401-10.

51. Chattopadhyay MK, Jagannadham MV, Vairamani M, Shivaji S. Carotenoid pigments of an antarctic psychrotrophic bacterium micrococcus roseus: temperature dependent biosynthesis, structure, and interaction with synthetic membranes. Biochem Biophys Res Commun. 1997;239:85-90.

52. Bredeston LM, Marciano D, Albanesi D, De Mendoza D, Delfino JM. Thermal regulation of membrane lipid fluidity by a two-component system in Bacillus subtilis. Biochem Mol Biol Edu. 2011:39:362-6.

53. Chintalapati S, Kiran MD, Shivaji S. Role of membrane lipid fatty acids in cold adaptation. Cellular and molecular biology (Noisy-le-Grand, France). 2004:50:631

54. Singh AK, Zhang Y, Zhu K, Subramanian C, Li Z, Jayaswal RK, et al. FabH selectivity for anteiso branched-chain fatty acid precursors in low-temperature adaptation in Listeria monocytogenes. FEMS Microbiol Lett. 2009;301:188-92.

55. Choi KH, Heath RJ, Rock CO. Beta -Ketoacyl-acyl carrier protein synthase III $(\mathrm{FabH})$ is a determining factor in branched-chain fatty acid biosynthesis. J Bacteriol. 2000;182:365-70.

56. Li Y, Florova G, Reynolds KA. Alteration of the fatty acid profile of streptomyces coelicolor by replacement of the initiation enzyme 3-Ketoacyl acyl carrier protein synthase III (FabH). J Bacteriol. 2005;187:3795-9.

57. $\mathrm{Yu}, \mathrm{Y}, \mathrm{Hu} Z$, Dong $\mathrm{H}, \mathrm{Ma} J$, Wang $\mathrm{H}$. Xanthomonas campestris FabH is required for branched-chain fatty acid and DSF-family quorum sensing signal biosynthesis. Sci Rep-Uk. 2016:6:32811.

58. Konkel ME, Tilly K. Temperature-regulated expression of bacterial virulence genes. Microbes Infect. 2000;2:157-66.

59. Smirnova A, Li H, Weingart $H$, Aufhammer S, Burse A, Finis K, et al. Thermoregulated expression of virulence factors in plant-associated bacteria. Arch Microbiol. 2001;176:393-9. 
60. Arvizu-Gomez JL, Hernandez-Morales A, Aguilar JR, Alvarez-Morales A. Transcriptional profile of P. Syringae pv. Phaseolicola NPS3121 at low temperature: physiology of phytopathogenic bacteria. BMC Microbiol. 2013;13:81.

61. Stead DE. Grouping of Xanthomonas campestris pathovars of cereals and grasses by fatty acid profiling. EPPO Bulletin. 1989;19:57-68.

62. Trapnell C, Williams BA, Pertea G, Mortazavi A, Kwan G, van Baren MJ, et al. Transcript assembly and quantification by RNA-Seq reveals unannotated transcripts and isoform switching during cell differentiation. Nat Biotechnol. 2010;28:511-5.

63. Trapnell C, Roberts A, Goff L, Pertea G, Kim D, Kelley DR, et al. Differential gene and transcript expression analysis of RNA-seq experiments with TopHat and cufflinks. Nat Protoc. 2012;7:562-78.

\section{Publisher's Note}

Springer Nature remains neutral with regard to jurisdictional claims in published maps and institutional affiliations.

Ready to submit your research? Choose BMC and benefit from:

- fast, convenient online submission

- thorough peer review by experienced researchers in your field

- rapid publication on acceptance

- support for research data, including large and complex data types

- gold Open Access which fosters wider collaboration and increased citations

- maximum visibility for your research: over $100 \mathrm{M}$ website views per year

At $\mathrm{BMC}$, research is always in progress.

Learn more biomedcentral.com/submissions 